\title{
Synthesis and Study \\ of Copper-Containing Polymers Based \\ on Sulfated Ethanol Lignin of Abies Wood
}

\author{
Natalia Yu. Vasilyeva*a,b, Alexander V. Levdansky ${ }^{a}$, \\ Alexander S. Kazachenko a, Nikolai G. Maximova, \\ Galina P. Skvortsova ${ }^{a}$, Maxim A. Lutoshkina, \\ Irina V. Korol'kova ${ }^{a}$ and Boris N. Kuznetsov ${ }^{a, b}$ \\ anstitute of Chemistry and Chemical Technology SB RAS \\ FRC "Krasnoyarsk Science Center SB RAS" \\ $50 / 24$ Akademgorodok, Krasnoyarsk, Russian Federation \\ ${ }^{b}$ Siberian Federal University \\ Krasnoyarsk, Russian Federation
}

Received 15.11.2016, received in revised form 10.10.2019, accepted 21.12.2019

\begin{abstract}
For the first time water soluble copper-containing polymers based on sulfated ethanol lignin of abies wood were obtained by the method of ion exchange. Their composition and structure were studied with the use of elemental and chemical analysis, infrared spectroscopy (IR), atomic absorption, electron paramagnetic resonance (EPR). The absence of nitrogen for copper cations in the resulting polymer indicates the complete substitution of ammonium cations in the ammonium salt of sulfated ethanol lignin. In EPR spectrum of copper-containing sulfated ethanol lignin there is a superposition of two signals. One of them belongs to isolated $\mathrm{Cu}^{2+}$ ions, the other to exchange-bound $\mathrm{Cu}^{2+}$ ions in salt-like compounds. The integral intensity of signal of isolated $\mathrm{Cu}^{2+}$ ions (anisotropic signal) and exchange-bound ions (isotropic signal) depends on the copper content in the polymer.
\end{abstract}

Keywords: sulfated ethanol lignin, abies wood, ion exchange, copper-containing polymers, isolated and exchange-bound $\mathrm{Cu}^{2+}$ ions.

Citation: Vasilyeva N.Yu., Levdansky A.V., Kazachenko A.S., Maximov N.G., Skvortsova G.P., Lutoshkin M.A., Korol'kova I.V., Kuznetsov B.N. Synthesis and study of copper-containing polymers based on sulfated ethanol lignin of abies wood, J. Sib. Fed. Univ. Chem., 2020, 13(1), 142-152. DOI: 10.17516/1998-2836-0170

(C) Siberian Federal University. All rights reserved

This work is licensed under a Creative Commons Attribution-NonCommercial 4.0 International License (CC BY-NC 4.0).

* Corresponding author E-mail address: inm@icct.ru 


\title{
Синтез и изучение медьсодержащих полимеров \\ на основе сульфатированного этаноллигнина \\ древесины пихты
}

\author{
Н.Ю. Васильева ${ }^{\mathrm{a}, \tilde{\sigma}}$, А.В. Левданский ${ }^{\mathrm{a}}$, \\ А.С. Казаченко ${ }^{\text {, Н.Г. Максимов }}{ }^{\text {, }}$,.П. Скворцова ${ }^{a}$, \\ М.А. Лутошкин ${ }^{\text {a }}$, И.В. Королькова ${ }^{\text {a }}$, Б.Н. Кузнецов ${ }^{\text {a, }}$,* \\ ${ }^{a}$ Институт химии и химической технологии СО РАН \\ ФИЦ «Красноярский научный центр СО РАН» \\ Российская Федерация, Красноярск \\ ${ }^{6}$ Сибирский федеральный университет \\ Российская Федераиия, Красноярск
}

Аннотация. Впервые методом ионного обмена осуществлен синтез водорастворимых медьсодержащих сульфатов этаноллигнина пихты сибирской. Изучены их состав и строение методами элементного и химического анализа, атомной абсорбции, инфракрасной спектроскопии (ИКС), электронного парамагнитного резонанса (ЭПР). Отсутствие азота в полученном полимере свидетельствует о полном замещении катионов аммония в аммонийной соли сульфата этаноллигнина на катионы меди. В спектре ЭПР медьсодержащего сульфата этаноллигнина наблюдается суперпозиция двух сигналов. Один из них принадлежит изолированным ионам $\mathrm{Cu}^{2+}$, другой - обменносвязанным ионам $\mathrm{Cu}^{2+}$ в солеобразных соединениях. Интегральная интенсивность сигналов изолированных ионов $\mathrm{Cu}^{2+}$ (анизотропный сигнал) и обменносвязанных ионов (изотропный сигнал) зависит от содержания меди в полимере.

Ключевые слова: сульфатированный этаноллигнин, древесина пихты, ионный обмен, медьсодержащие полимеры, изолированные и обменносвязанные ионы $\mathrm{Cu}^{2+}$.

Цитирование: Васильева, Н.Ю. Синтез и изучение медьсодержащих полимеров на основе сульфатированного этаноллигнина древесины пихты / Н.Ю. Васильева, А.В. Левданский, А.С. Казаченко, Н.Г. Максимов, Г.П. Скворцова, М.А. Лутошкин, И.В. Королькова, Б.Н. Кузнецов // Журн. Сиб. федер. ун-та. Химия, 2020. 13(1). С. 142-152. DOI: $10.17516 / 1998-2836-0170$

\section{Введение}

Лигнин представляет собой природный полифенольный полимер, присутствующий в клетках растений, наряду с целлюлозой и гемицеллюлозами $[1,2]$. Лигнин состоит из основных структурных звеньев (фенилпропановых единиц), содержащих в качестве заместителей различные органические группы, в том числе карбоксильные, эфирные и спиртовые [2].

Лигнины, выделенные из лигноцеллюлозной биомассы различными способами, отличаются по составу и свойствам. В процессах делигнификации лигнин претерпевает значительные структурные изменения, и реакционная способность выделенных лигнинов может существенно отличаться от таковой, характерной для нативного лигнина древесины. 
В последние годы разрабатывают новые способы получения целлюлозы, основанные на процессах органосольвентной варки древесины в присутствии различных органических растворителей, таких как метанол, этанол, уксусная и муравьиная кислоты. Одной из основных предпосылок для разработки процессов органосольвентной варки является их более высокая экологическая безопасность по сравнению с сульфатными и сульфитными технологиями делигнификации. Органосольвентные лигнины не содержат серы, обладают достаточно узким молекулярно-массовым распределением и относительно небольшой молекулярной массой [35]. Они химически более активны, чем технические лигнины, хорошо растворяются в органических растворителях, что облегчает их дальнейшую химическую переработку [6-9].

Одним из перспективных направлений переработки лигнина считают получение производных, содержащих сульфатную группу. Наличие сульфатной группы придает лигнину способность растворяться в воде и увеличивает его биоразлагаемость [10]. Сульфатированные производные лигнина могут не только заменить широко используемые продукты химической модификации полисахаридов, но и найти применение в фармацевтике как потенциальные противовирусные препараты и антикоагулянты нового класса [11-14].

Предмет интенсивных исследований - металлсодержащие полимерные материалы. Разнообразие металлов и органических полимеров открывает перспективы применения металлополимеров с регулируемыми физическими и химическими свойствами в различных новых областях: в качестве электрооптических, магнитных и сенсорных устройств, наноматериалов, катализаторов, лекарственных средств и систем доставки лекарств [15-17].

Модификацию макромолекулярных металлокомплексов, у которых ион металла находится в боковой цепи органического полимера, можно осуществлять с участием их функциональных групп, например, с помощью химических реакции солей металлов (сульфата меди) $[18,19]$. При этом сульфатированный этаноллигнин, будучи полианионом, способен к ионному обмену с катионами металлов.

Целью данного исследования являлась разработка простого способа синтеза водорастворимых медьсодержащих полимеров сульфатированного этаноллигнина древесины пихты, основанного на ионном обмене, и изучение их строения методами ИК- и ЭПР-спектроскопии.

\section{Экспериментальная часть}

В работе использовали этаноллигнин, выделенный из древесины пихты сибирской (Ábies sibirica). Извлечение этаноллигнина из обессмоленной древесины пихты осуществляли экстракцией смеси этанол-вода при температуре $185{ }^{\circ} \mathrm{C}$ и последующим осаждением холодной водой по методике [5].

Сульфатирование этаноллигнина проводили сульфаминовой кислотой в 1,4-диоксане с последующим выделением сульфатированного продукта в виде аммониевой соли (содержание серы $7.8 \%$ масс.) по методике, описанной в работе [20].

Медьсодержащие производные сульфатированного этаноллигнина получали из его аммониевой соли методом ионного обмена с использованием ионообменной смолы КУ-2-8 в $\mathrm{Cu}^{2+}$ форме по методикам, применяемый при синтезе медьсодержащих сульфатов микрокристаллической целлюлозы и арабиногалактана $[18,19]$. Для этого катионит КУ-2-8, выпускаемый в

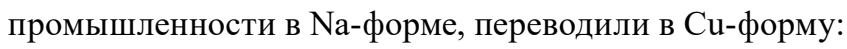




$$
\mathrm{R}-\mathrm{SO}_{3} \mathrm{Na}+\mathrm{Cu}^{2+} / 2 \rightarrow \mathrm{R}-\mathrm{SO}_{3}\left(\mathrm{Cu}^{2+}\right)+\mathrm{Na}^{+}
$$

где R - матрица смолы КУ-2-8.

Затем осуществляли ионный обмен катионов аммония в сульфатированном этаноллигнине (СЭЛ) на ионы меди $\mathrm{Cu}^{2+}$ :

$$
\text { СЭЛ- } \mathrm{OSO}_{3} \mathrm{NH}_{4}+\mathrm{R}-\mathrm{SO}_{3}\left(\mathrm{Cu}^{2+} / 2\right) \rightarrow \text { СЭЛ- } \mathrm{OSO}_{3}\left(\mathrm{Cu}^{2+} / 2\right)+\mathrm{R}-\mathrm{SO}_{3} \mathrm{NH}_{4} \text {. }
$$

Ионный обмен проводили в динамическом режиме при соотношении содержания обменных ионов в КУ-2-8 к содержанию ионов $\mathrm{NH}_{4}{ }^{+}$, равном 60 70:1 (мг/экв : мг/экв).

Образцы, отличающиеся различным содержанием меди (2.6, 3.8, 5.1, 7.9 \% масс.), были получены ионным обменом в статическом режиме при различном соотношении содержания ионов $\mathrm{Cu}^{2+}$ в катионите и групп $-\mathrm{OSO}_{3}{ }^{-}$в сульфатированном этаноллигнине.

Ионы меди (II) в медьсодержащем полимере сульфатированного этаноллигнина определяли методами комплексонометрического титрования ЭДТА с индикатором мурексид [21] и атомной абсорбции на спектрометре AAnalist-400 Perkin Elmer.

Элементный анализ сульфатированного этаноллигнина и медьсодержащего производного сульфатированного этаноллигнина пихты осуществляли на элементном анализаторе Flash EA1112 (Thermo Quest Italia).

ИК-спектры образцов регистрировали с использованием ИК-Фурье спектрометра IR Tracer-100 (Shimadzu, Япония) в области длин волн 400-4000 см-1. Обработку спектральной информации проводили по программе OPUS (версия 5.0). Твердые образцы для анализа готовили в виде таблеток в матрице $\mathrm{KBr}$ (2 мг образца / 1000 мг KBr). Отнесение полос было проведено с учетом литературных данных [22].

Спектры ЭПР регистрировали на приборе ЭПР Фурье-спектрометр «Bruker ELEXSYS E580» в режиме $\mathrm{CW}$ при комнатной температуре. Мощность CВЧ 0,2 мВт, величина модуляции 1 Гc (Gs). Моделировали спектры с помощью программ X Sophe, взаимное вычитание спектров осуществляли с помощью встроенных программ.

\section{Результаты и обсуждение}

Содержание меди в образце медьсодержащего сульфатированного этаноллигнина (CuСЭЛ), определенное различными методами (комплексонометрическим титрованием ЭДТА и методом атомной абсорбции), совпадает (табл. 1). Отсутствие азота в полученном продукте свидетельствует о полном замещении катионов аммония на катионы меди.

Образцы медьсодержащего сульфатированного лигнина представляют собой водорастворимые аморфные порошки темно-коричневого цвета. Обнаружено, что в процессе хранения эти образцы претерпевают химические изменения, в результате чего перестают полностью растворяться в воде.

В отличие от образца исходного этаноллигнина в ИК-спектре аммонийной соли сульфатированного этаноллигнина (рис. 1) появляются новые интенсивные полосы поглощения в области 803-761 см-1, соответствующие $\mathrm{C}-\mathrm{O}-\mathrm{S}$-валентным колебаниям $\mathrm{SO}_{3}$-группы, и широкие полосы поглощения в области 1270-1200 $\mathrm{cm}^{-1}$, относящейся к асимметричным валентным колебаниям группы $\mathrm{O}=\mathrm{S}=\mathrm{O}$ и скелетным колебаниям гваяцильного кольца [22]. В ИК-спектре образца Сu-СЭЛ (рис. 1) присутствует полоса поглощения при 817 см$^{-1}$, соответствующая 
Таблица 1. Результаты исследования элементного состава образца медьсодержащего сульфатированного этаноллигнина

Table 1. Results of the study of the elemental composition of the sample of copper-containing sulfated ethanol lignin

\begin{tabular}{|c|c|c|}
\hline \multirow{2}{*}{ Элемент } & \multicolumn{2}{|c|}{ Содержание, \% (масс.) } \\
\cline { 2 - 3 } & \multicolumn{2}{|c|}{ Метод определения } \\
\cline { 2 - 3 } & Химический & Атомная адсорбция \\
\hline $\mathrm{Cu}$ & 8.0 & 7.9 \\
\hline $\mathrm{S}$ & 7.8 & - \\
\hline $\mathrm{N}$ & - & - \\
\hline
\end{tabular}

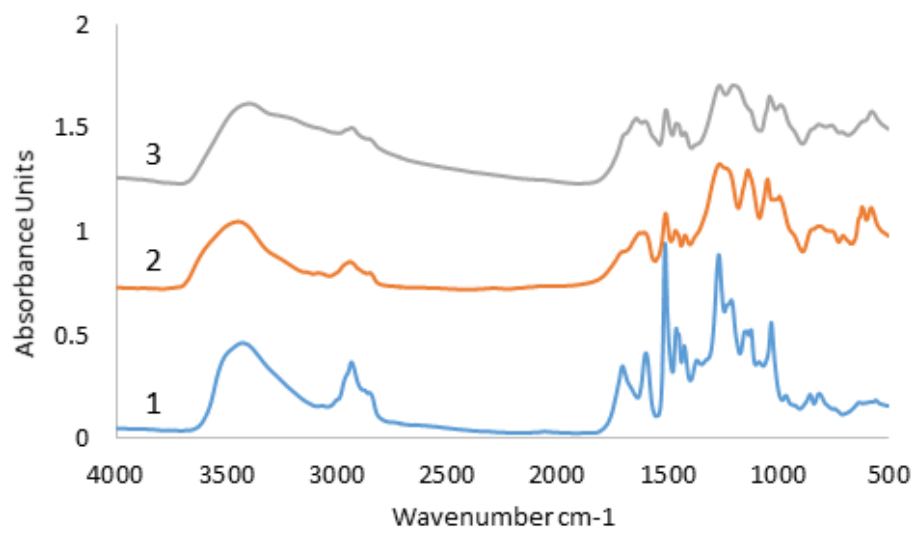

Рис. 1. ИК-спектры образцов: 1 - этаноллигнин пихты; 2 - аммонийная соль сульфатированного этаноллигнина пихты; 3 - медьсодержащий сульфатированный этаноллигнин пихты

Fig. 1. FTIR spectra of samples: 1 - abies ethanol lignin; 2 - ammonium salt of sulfated abies ethanol lignin; 3 - copper-containing sulfated abies ethanol lignin

C-O-S-валентным колебаниям сульфатной группы. Полосы поглощения в области 3397 $2933 \mathrm{~cm}^{-1}$ соответствуют валентным колебаниям О-Н- и C-Н-связей. Наблюдается уширение и расщепление полос поглощения в области 1257-1205 $\mathrm{cm}^{-1}$, соответствующих валентным колебаниям сульфатных групп, связанных с катионами $\mathrm{Cu}^{2+}$.

Образцы Сu-СЭЛ с различным содержанием меди были изучены методом ЭПР.

Спектры ЭПР этих образцов содержат два типа сигналов (рис. 2-6). Сигналы типа 1 - это анизотропные сигналы от ионов $\mathrm{Cu}^{2+}$ с характерными значениями g-факторов и величин констант сверхтонкой структуры (CTC) от ядер изотопов меди (I=3/2). Сигналы типа 2 близки к симметричным.

Известно, что между парамагнитными центрами имеются два типа взаимодействий: диполь-дипольное (приводящее к уширению сигналов ЭПР) и обменное (как правило, приво-

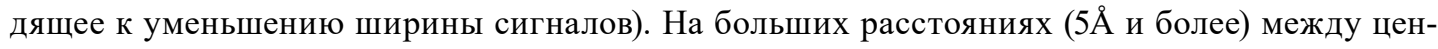
трами преобладает диполь-дипольное взаимодействие. С уменьшением расстояния происходит рост обменных взаимодействий за счет перекрывания орбит неспаренных электронов (прямого или через общие лиганды). Появление симметричного сигнала (рис. 2-5), интен- 


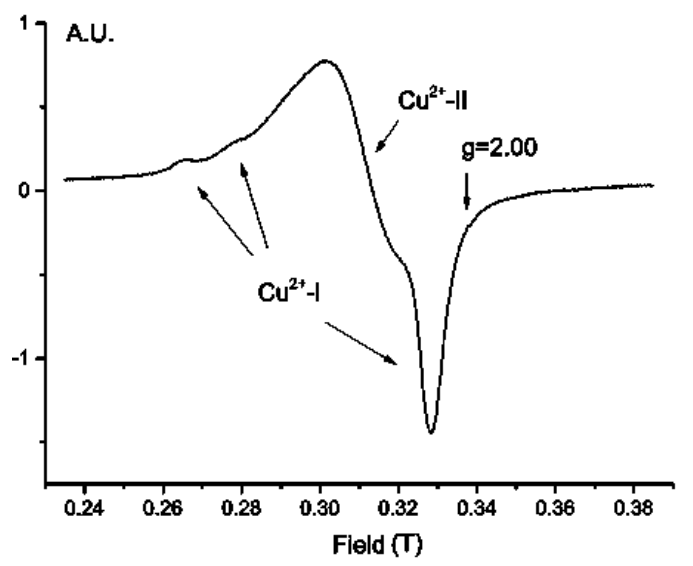

Рис. 2. Спектр ЭПР образца Сu-СЭЛ (содержание меди $2.6 \%$ масс.; $\mathrm{T}_{\text {изм }} 25^{\circ} \mathrm{C}$ )

Fig. 2. EPR spectrum of a Cu-SEL sample (2.6\% of copper, $\left.\% \mathrm{wt} ; \mathrm{T}_{\text {measurement }} 25^{\circ} \mathrm{C}\right)$

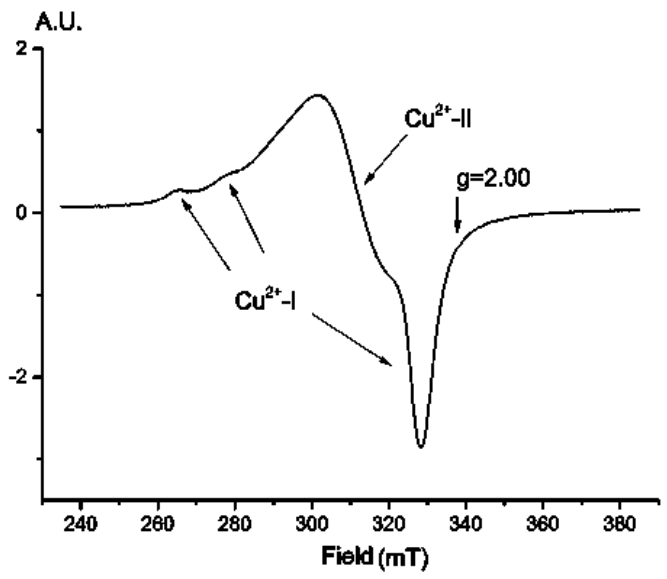

Рис. 3. Спектр ЭПР образца Сu-СЭЛ (содержание меди $3.8 \%$ масс.; $\mathrm{T}_{\text {изм }} 25^{\circ} \mathrm{C}$ )

Fig. 3. EPR spectrum of a Cu-SEL sample $\left(3.8 \%\right.$ of copper, $\left.\% \mathrm{wt} ; \mathrm{T}_{\text {measurement }} 25^{\circ} \mathrm{C}\right)$

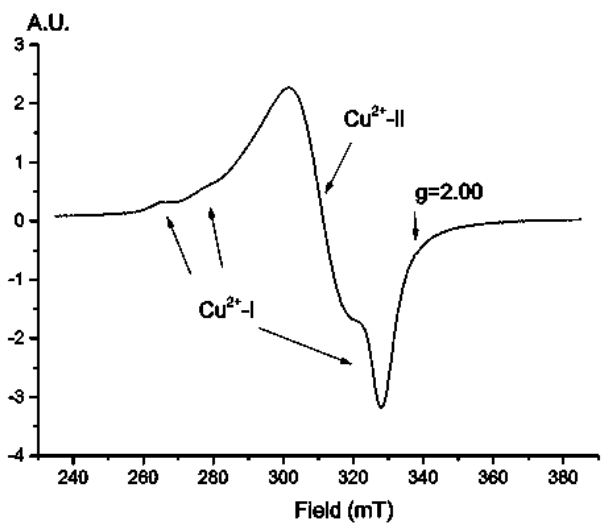

Рис. 4. Спектр ЭПР образца Сu-СЭЛ (содержание меди $5.1 \%$ масс.; $\mathrm{T}_{\text {изм }} 25^{\circ} \mathrm{C}$ )

Fig. 4. EPR spectrum of a Cu-SEL sample (5.1\% of copper, $\%$ wt; $\left.\mathrm{T}_{\text {measurement }} 25^{\circ} \mathrm{C}\right)$

$$
\text { - } 147 \text { - }
$$




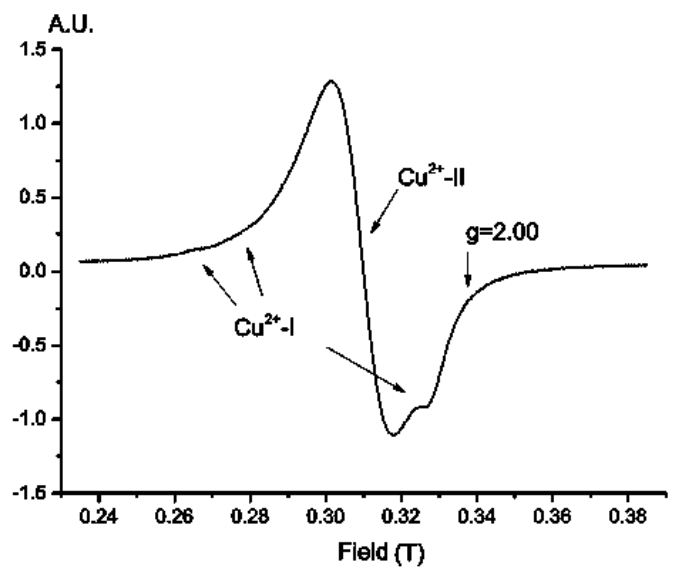

Рис. 5. Спектр ЭПР образца Сu-СЭЛ (содержание меди $7.9 \%$ масс.; $\mathrm{T}_{\text {изм }} 25^{\circ} \mathrm{C}$ )

Fig. 5. EPR spectrum of a Cu-SEL sample ( $7.9 \%$ of copper, $\% \mathrm{wt}$; $\left.\mathrm{T}_{\text {measurement }} 25{ }^{\circ} \mathrm{C}\right)$

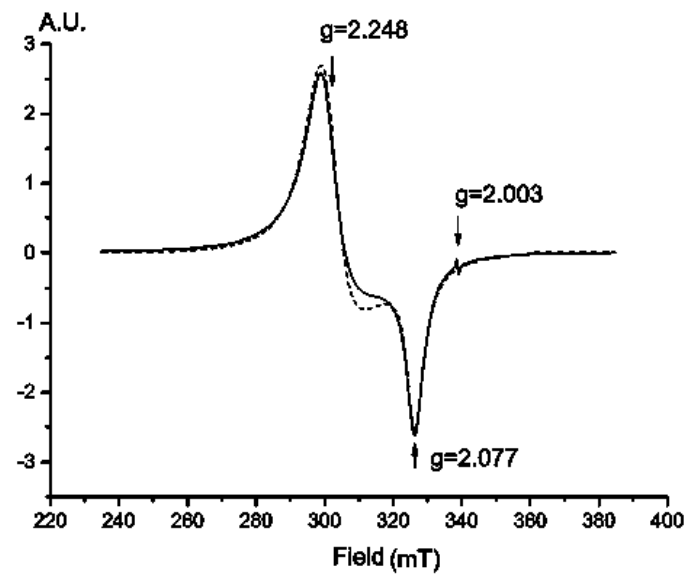

Рис. 6. Спектр ЭПР (сплошная линия) образца Сu-СЭЛ после химической трансформации в процессе хранения (содержание меди $7.9 \%$ масс.; $\mathrm{T}_{\text {изм }} 25^{\circ} \mathrm{C}$ ) и модельный спектр ЭПР (пунктирная линия)

Fig. 6. EPR spectrum (solid line) of Cu-SEL sample after chemical transformation during storage $(7.9 \%$ of copper, \% wt; $\mathrm{T}_{\text {measurement }} 25^{\circ} \mathrm{C}$ ) and the EPR model spectrum (dashed line)

сивность которого с ростом содержания меди меняется более чем на порядок при сохранении ширины (табл. 2), свидетельствует о постоянстве средних расстояний между катионами меди. Аналогичные сигналы в спектрах ЭПР наблюдаются при исследовании различных соединений меди (II) $[23,24]$. Появление симметричных сигналов указывает на отсутствие упорядоченных кристаллических решеток в образовавшихся соединениях меди (II) в образцах $\mathrm{Cu}-\mathrm{CЭЛ.} \mathrm{Подобное} \mathrm{состояние} \mathrm{реализуется} \mathrm{в} \mathrm{неупорядоченных} \mathrm{соединениях} \mathrm{(например,}$ в стеклах).

Установлено, что параметры спектров ЭПР определяются составом и строением координационной сферы катионов $\mathrm{Cu}^{2+}$ [23-25]. Координационное состояние меди в образцах $\mathrm{Cu}-\mathrm{CЭЛ}$ определяется присутствием в ближайшем окружении наряду с молекулами воды кислородсодержащих групп сульфатированного лигнина, которые образуют с катионами меди более проч- 
Таблица 2. Изменение параметров сигналов ЭПР в зависимости от содержания меди (II) в образцах $\mathrm{Cu}-$ СЭЛ*

Table 2. Changing the parameters of EPR signals according to the content of copper (II) in the samples CuSEL*

\begin{tabular}{|l|c|c|c|c|}
\hline \multicolumn{1}{|c|}{$\begin{array}{c}\text { Содержание } \\
\text { меди \% (масс.) }\end{array}$} & 2.6 & 3.8 & 5.1 & 7.9 \\
\hline $\begin{array}{l}\text { Изолированные } \\
\text { ионы } \mathrm{Cu}^{2+}\end{array}$ & $\begin{array}{l}\mathrm{g}_{1}=2.379 \mathrm{~g}_{2}=2.070 \\
\mathrm{~g}_{\mathrm{cp}}=2.173 \mathrm{~A}=128 \mathrm{G}\end{array}$ & $\begin{array}{l}\mathrm{g}_{1}=2.381 \mathrm{~g}_{2}=2.070 \\
\mathrm{~g}_{\mathrm{cp}}=2.174 \mathrm{~A}=128 \mathrm{G}\end{array}$ & $\begin{array}{l}\mathrm{g}_{1}=2.385 \mathrm{~g}_{2}=2.073 \\
\mathrm{~g}_{\mathrm{cp}}=2.177 \mathrm{~A}=123 \mathrm{G}\end{array}$ & не определены \\
\hline $\begin{array}{l}\text { Ионы } \mathrm{Cu}^{2+} \text { в } \\
\text { стеклообразном } \\
\text { состоянии }\end{array}$ & $\mathrm{g}=2.170 \Delta \mathrm{H}=210 \mathrm{G}$ & $\mathrm{g}=2.170 \Delta \mathrm{H}=210 \mathrm{G}$ & $\mathrm{g}=2.174 \Delta \mathrm{H}=190 \mathrm{G}$ & $\mathrm{g}=2.181 \Delta \mathrm{H}=170 \mathrm{G}$ \\
\hline $\mathrm{I}_{\text {инд }} / \mathrm{I}_{\text {сол }}$ & 1 & 0.8 & 0.4 & 0.07 \\
\hline
\end{tabular}

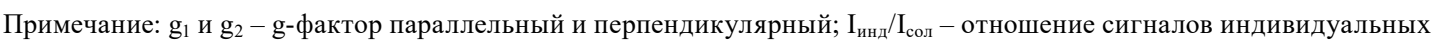
ионов и солевых состояний; А - константа СТС параллельной ориентации.

ные связи. Это подтверждается изменением параметров ЭПР индивидуальных парамагнитных центров (табл. 2) с ростом содержания меди. Анализ спектров ЭПР показал, что катионы $\mathrm{Cu}^{2+}$ в медьсодержащих полимерах СЭЛ находятся в октадрическом кислородном окружении в виде изолированных ионов на участках с малой локальной концентрацией сульфатных групп и в виде солеобразных соединений на участках с высоким локальным содержанием сульфатных групп. Для сравнения отметим, что в местах с высоким локальным содержанием сульфатных групп медные производные сульфатированной микрокристаллической целлюлозы представляют солевую систему, имеющую псевдокристаллическое строение [18], а медные производные сульфатированного арабиногалактана находятся в виде частично упорядоченных солеподобных соединений [19].

На рис. 6 представлен спектр ЭПР образца Сu-СЭЛ (содержания серы 7.8 \% масс.) после хранения в атмосфере воздуха в течение 2 месяцев. Наличие анизотропии сигнала ЭПР этого образца $\mathrm{g}$ (параллельное) $=2.077$ и $\mathrm{g}($ перпендикулярное $)=2.248$, при отсутствии СТС свидетельствует об образовании солевых соединений меди (II). Значение g-факторов этого соединения соответствует g-факторам кристаллических солей меди [23-25]. Образование подобного солевого соединения обусловлено деградацией исходных соединений меди по радикальному механизму. Об этом свидетельствует появление сигналов от свободных радикалов ( $\mathrm{g}=2.00)$ в спектре ЭПР (рис. 6). Этот процесс радикальной деградации Сu-СЭЛ и приводит к образованию нерастворимого в воде солевого соединения.

\section{Заключение}

В результате проведенного исследования установлена возможность использования метода ионного обмена для получения медьсодержащих полимеров на основе сульфатированного этаноллигнина с регулируемым соотношением изолированных и обменносвязанных ионов $\mathrm{Cu}^{2+}$.

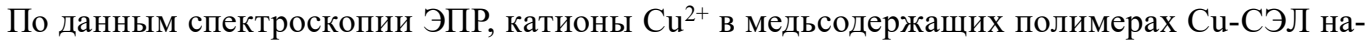
ходятся в октадрическом кислородном окружении в виде изолированных ионов на участках с малой локальной концентрацией сульфатных групп и в солеподобном состоянии на участках с высоким локальным содержанием сульфатных групп. 


\section{Благодарности / Acknowledgements}

Исследование выполнено за счет средств Российского научного фонда (грант № 16-1310326). В работе использованы приборы Красноярского регионального центра коллективного пользования ФИЦ КНЦ СО РАН.

The reported study was supported by Russian Science Foundation (Grant No. 16-13-10326). This work was conducted using the equipment of Krasnoyarsk Regional Research Equipment Centre of SB RAS.

\section{Список литературы / References}

1. Calvo-Flores F.G., Dobado J.A., Isac-García J., Martin-Martinez F. Lignin and lignans as renewable raw materials: chemistry, technology and applications. Chichester: Wiley, 2015. $482 \mathrm{p}$

2. Wool R.P., Sun X.S. Bio-based polymers and composites. Boston: Elsevier Academic Press, 2005. $640 \mathrm{p}$.

3. Кузнецов Б.Н., Маляр Ю.Н., Кузнецова С.А., Гришечко Л.Н., Казаченко А.С., Левданский А.В., Пестунов А.В., Бояндин А.Н., Селзард А. Выделение, изучение и применение органосольвентных лигнинов (обзор). Журнал Сибирского федерального университета. Химия 2016. T. 9(4), C. 454-482. [Kuznetsov B.N., Malyar Yu.N., Kuznetsova S.A., Grishechko L.I., Kazachenko A.S., Levdansky A.V., Pestunov A.V., Boyandin A.N., Celzard A. Isolation, study and application of organosolv lignins (review). J. Sib. Fed. Univ. Chem. 2016. Vol. 9(4), P. 454-482. (In Russ.)].

4. De la Torre M.J., Moral A., Hernández M.D., Cabeza E., Tijero A. Organosolv lignin for biofuel. Ind. Crops Prod. 2013. Vol. 45, P. 58-63.

5. Quesada-Medina J., López-Cremades F.J., Olivares-Carrillo P. Organosolv extraction of lignin from hydrolyzed almond shells and application of the $\delta$-value theory. Bioresour. Technol. 2010. Vol. 101(21), P. 8252-8260.

6. Schutyser W., Renders T., Van den Bosch S., Koelewijn S.-F., Beckham G.T., Sels B.F. Chemicals from lignin: an interplay of lignocellulose fractionation, depolymerisation, and upgrading. Chem. Soc. Rev. 2018. Vol. 47(3), P. 852-908.

7. Agrawal A., Kaushik N., Biswas S. Derivatives and applications of lignin - an insight. The Scitech Journal 2014. Vol. 1(7), P. 30-36.

8. Gilca I.A., Ghitescu R.E., Puitel A.C., Popa V.I. Preparation of lignin nanoparticles by chemical modification. Iran. Polym. J. 2014. Vol. 23(5), P. 355-363.

9. Vinardell M.P., Mitjans M. Lignins and their derivatives with beneficial effects on human health. Int. J. Mol. Sci. 2017. Vol. 18(6), P. 1219.

10. Prinsen P., Narani A., Hartog A.F, Wever R., Rothenberg G. Dissolving lignin in water through enzymatic sulfation with aryl sulfotransferase. ChemSusChem. 2017. Vol. 10(10), P. 2267-2273.

11. Raghuraman A., Tiwari V. Zhao Q., Shukla D., Debnath A.K., Desai U.R. Viral inhibition studies on sulfated lignin, a chemically modified biopolymer and a potential mimic of heparan sulfate. Biomacromolecules 2007. Vol. 8(5), P. 1759-1763.

12. Henry B.L., Desai U.R. Sulfated low molecular weight lignins, allosteric inhibitors of coagulation proteinases via the heparin binding site, significantly alter the active site of thrombin and factor xa compared to heparin. Thromb Res. 2014. Vol. 134(5), P. 1123-1129. 
13. Thakkar J.N. Discovery of lignin sulfate as a potent inhibitor of HSV entry cells. Theses and dissertations graduate school, Virginia Commonwealth University, 2006. 132 p.

14. Raghuraman A., Tiwari V., Thakkar J.N., Gunnarsson G.T., Shukla D., Hindle M., Desai U.R. Structural characterization of a serendipitously discovered bioactive macromolecule, lignin sulfate. Biomacromolecules 2005. Vol. 6(5), P. 2822-2832.

15. Manners I. Synthetic metal-containing polymers. Weinheim: Wiley, 2004. 288 p.

16. Yan Y., Zhang J., Ren L., Tang C. Metal-containing and related polymers for biomedical applications. Chem. Soc. Rev. 2016. Vol. 45(19), P. 5232-5263.

17. Сибикина О.В., Иозеп А.А., Москвин А.В. Комплексы полисахаридов с катионами металлов: применение и строение (обзор). Хим.-фарм. журн. 2009. Т. 43(6), С. 35-39. [Sibikina O.V., Iozep A.A., Moskvin A.V. Polysaccharide complexes with metal cations: structure and application (a review). Pharm. Chem. J. 2009. Vol. 43(6), P. 341-345 (In Russ.)]

18. Levdansky A.V., Vasilyeva N.Yu., Maximov N.G., Karacharov A.A., Levdansky V.A., Skvortsova G.P., Kuznetsov B.N., Djakovitch L., Pinel C. Synthesis and study of copper-containing polymers of microcrystalline cellulose sulfates from Larch wood. Russ J. Bioorg. Chem. 2018. Vol. 44(7), P. 834-838.

19. Kuznetsov B.N., Vasilyeva N.Yu., Levdansky A.V., Maximov N.G., Kazachenko A.S., Skvortsova G.P., Djakovitch L., Pinel C. Synthesis and study of copper-containing polymers based on sulfated arabinogalactan. Russ J. Bioorg. Chem. 2017. Vol. 43(7), P. 727-731.

20. Кузнецов Б.Н., Васильева Н.Ю., Казаченко А.С., Скворцова Г.П., Левданский В.А., Лутошкин М.А. Разработка метода сульфатирования этаноллигнина древесины пихты с использованием сульфаминовой кислоты. Журнал Сибирского федерального университета. Химия 2018. T. 11(1), C. 122-130. [Kuznetsov B.N., Vasilyeva N.Yu., Kazachenko A.S., Skvortsova G.P., Levdansky V.A., Lutoshkin M.A. Development of the method of abies wood ethanollignin sulfonation using sulfamic acid, J. Sib. Fed. Univ. Chem. 2018, Vol. 11(1), P. 122-130. (In Russ.)]

21. Подчайнова В.Н., Симонова Л.Н. Аналитическая химия элементов. Медь. М.: Наука, 1990, 279 c. [Podchaynova V.N., Simonova L.N. Analytical chemistry of elements. Copper. M.: Nauka, 1990, 297 p. (In Russ.)]

22. Roeges N.P.G. A guide to the complete interpretation of infrared spectra of organic structures. NewYork: Wiley, 1994, 340 p.

23. Красильникова С.В., Грунин Ю.Б., смирнова Л.Г. Вишневская Г.П., Хонг Я.Ш., Ли Ч.Х., Волков В.И. Особенности взаимодействия ионов $\mathrm{Cu}^{2+}$ и $\mathrm{Mn}^{2+}$ с ионообменной целлюлозой по данным электронного парамагнитного резонанса. Структура и динамика молекулярных систем 2007. T. 1, C. 454-457. [Krasil'nikova S.V., Grunin Yu.B., Smirnova L.G., Vishnevskaya G.P., Khong Ya.Sh., LiCh.Kh., Volkov V.I. Features of interaction of $\mathrm{Cu}^{2+}$ and the $\mathrm{Mn}^{2+}$ ions with ion-exchange cellulose according to electronic paramagnetic resonance. Structure and dynamics of molecular systems 2007. Vol. 1, P. 454-457. (In Russ.)]

24. Молочников Л.С., Пестов А.В., Заболоцкая Е.В., Ятлук Ю.Г. Строение комплексов меди с N-(2-карбоксиэтил)хитозаном в твердой фазе. Журнал прикладной спектроскопии 2008, T. 75(5), C. 648-652. [Molochnikov L.S., Pestov A.V., Yatluk Yu.G., Zabolotskaya E.V. Solid-state structure of copper complexes of N-(2-carboxyethyl)chitosan. J. Appl. Spectroscop. 2008. Vol. 75(5). P. 648-652 (In Russ.)] 
25. Васенин Н.Т., Ануфриенко В.Ф., Шутилов Р.А., Зенковец Г.А., Шубин А.А., Гаврилов В.Ю., Пармон В.Н. Орбитальное упорядочение ионов $\mathrm{Cu}^{2+}$ в концентрированных водноаммиачных растворах хлорида, сульфата и ацетата меди по данным ЭПР. Доклады Академии наук 2013, T. 450(1), C. 50-53. [Vasenin N.T., Anufrienko V.F., Shutilov R.A., Zenkovets G.A., Shubin A.A., Gavrilov V.Y., Parmon V.N. Orbital ordering of $\mathrm{Cu}^{2+}$ ions in concentrated aqueous ammonia solutions of copper chloride, sulfate, and acetate as probed by ESR. Doklady Physical Chemistry 2013. Vol. 450(1), P. 103-106.(In Russ.)] 